\section{Spatial distribution of dengue incidence and socio-environmental conditions in Campinas, São Paulo State, Brazil, 2007}

\author{
Distribuição espacial da incidência de dengue e \\ condições socioambientais em Campinas, \\ Estado de São Paulo, Brasil, 2007 \\ Distribución espacial de la incidencia de dengue y \\ condiciones socioambientales en Campinas, \\ estado de São Paulo, Brasil, 2007
}

José Vilton Costa 1

Maria Rita Donalisio 1

Liciana Vaz de Arruda Silveira 2

\footnotetext{
${ }^{1}$ Faculdade de Ciências Médicas, Universidade Estadual de Campinas, Campinas, Brasil.

2 Instituto de Biociências, Universidade Estadual Paulista Julio de Mesquita Filho, Botucatu, Brasil.

Correspondence

J. V. Costa

Departamento de Saúde

Coletiva, Faculdade

de Ciências Médicas,

Universidade Estadual de Campinas.

Rua Tessália Vieira de Camargo 126, Campinas, SP 13083-887, Brasil. josevilton@gmail.com
}

\begin{abstract}
This study aimed to analyze the spatial distribution of dengue risk and its association with socio-environmental conditions. This was an ecological study of the counts of autochthonous dengue cases in the municipality of Campinas, São Paulo State, Brazil, in the year 2007, aggregated according to 47 coverage areas of $m u$ nicipal health centers. Spatial models for mapping diseases were constructed with Bayesian hierarchical models, based on Integrated Nested Laplace Approximation (INLA). The analyses were stratified according to two age groups, 0 to 14 years and above 14 years. The results indicate that the spatial distribution of dengue risk is not associated with socio-environmental conditions in the 0 to 14 year age group. In the age group older than 14 years, the relative risk of dengue increases significantly as the level of socio-environmental deprivation increases. Mapping of socio-environmental deprivation and dengue cases proved to be a useful tool for data analysis in dengue surveillance systems.
\end{abstract}

Dengue; Social Conditions; Small-Area Analysis; Epidemiological Surveillance

\section{Resumo}

O objetivo deste estudo foi analisar a distribuição espacial do risco de dengue e a sua relação com condições socioambientais. Trata-se de um estudo ecológico da contagem dos casos de dengue autóctone, no Município de Campinas, Estado de São Paulo, Brasil, no ano de 2007, agregados em 47 áreas de cobertura dos Centros de Saúde do município. Modelos espaciais de mapeamento de doenças foram construídos utilizando-se modelos hierárquicos bayesianos, por meio do método de Integração Aproximada Aninhada de Laplace (INLA). As análises foram estratificadas segundo os grupos etários até 14 anos e acima de 14 anos. Os resultados indicam que a distribuição espacial do risco de dengue não está associada a condições socioambientais para o grupo etário até 14 anos. No grupo etário acima de 14 anos, o risco relativo de dengue aumenta significativamente conforme aumenta $o$ nível de carência socioambiental. O mapeamento dos estratos de carência socioambiental e dos casos de dengue mostrou-se uma ferramenta útil na análise dos dados dos sistemas de vigilância de dengue.

Dengue; Condições Sociais; Análise de Pequenas Áreas; Vigilância Epidemiológica 


\section{Introduction}

Dengue fever is a vector-borne viral disease caused by one of four serotypes of the dengue virus (DENV-1 to DENV-4) belonging to genus Flavivirus, family Flaviviridae. Dengue is currently considered one of the world's most serious public health problems, with some 100 million cases worldwide and 2.5 billion people living in areas at risk of infection. Dengue is endemic in tropical regions such as Southeast Asia, South $\mathrm{Pa}$ cific, East Africa, Caribbean, and Latin America (Ministério da Saúde. http://portal.saude.gov. br/portal/arquivos/pdf/casos_de_dengue_clas sica_brasil_1990_2011.pdf, accessed on 20/ Jun/2012). In Brazil, the Southeast region has the largest number of reported dengue cases per year. The country's other regions by order of dengue incidence are the Northeast, Central-West, South, and North 1.

The increasing circulation of the various serotypes, with different genotypes of the virus, and the (re)introduction of new dengue virus serotypes in Brazil have resulted in the "endemicization" and hyperendemicity of the disease, with changes in its epidemiological profile. This trend has been associated with both increasing incidence in children less than 14 years of age and the proportion of severe cases 2 .

In the municipality of Campinas, São Paulo State, the first reported autochthonous dengue case was in 1996. The disease has been reported every year since then, with three epidemics involving higher transmission, in 1998, 2002, and 2007. In the latter year a total of 11,519 cases were reported, and three different circulating serotypes were detected: DENV-1, DENV-2, and DENV-3. The historical case series since 1998 shows that the period with highest incidence of the disease is in the months of March and April in Campinas 3, as observed in other municipalities 4 .

The reasons for the reemergence and expansion of dengue in Brazil in recent decades are complex. Some authors point to the association between dengue incidence and climatic conditions (increasing temperature, rainfall, and relative humidity) 5,6 . Accelerated population growth, intense human migratory waves to urban peripheries lacking adequate infrastructure, and the deterioration of living and health conditions are contributing factors to increasing infestation by the principal dengue vector, Aedes aegypti 5 , and the resulting spread of the disease 7 .

Currently, with no specific treatment and still no effective vaccine available, one of the existing forms of dengue prevention is to control the mosquito vector 8 . Thus, understanding the spatial dimensions of dengue transmission in differ- ent epidemiological contexts can help increase the understanding of dengue virus transmission dynamics and assist the planning of preventive and emergency control measures ${ }^{9}$.

The different dimensions of dengue transmission resulting from interaction between the human population, vectors, and viral circulation require approaches from various disciplines and areas of knowledge. Among the latter, spatial analysis allows evaluating the distribution of health events at different levels of geographic aggregation 9,10,11. Such analyses have been used to assess dengue distribution in the urban space, in the identification of regions at increased risk, and in the search for factors potentially associated with risk in different regions 12,13.

The aim of this study was to analyze the spatial distribution of dengue incidence in the coverage areas of municipal health centers in Campinas and to assess possible associations with socioenvironmental conditions.

\section{Material and methods}

\section{Study location and design}

This was an ecological study on the spatial distribution of autochthonous dengue cases in the municipality of Campinas, with the Municipal Health Center Coverage Areas (ACCS in Portuguese) as the unit of analysis. This unit of analysis was chosen due to its importance as a territory specifically demarcated for planning and managing health services, besides serving as the locus for interaction between health services and the organized population (local health councils).

Campinas is located in central-western São

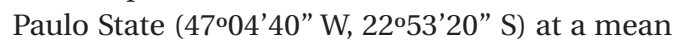
altitude of $640 \mathrm{~m}$ above sea level. The municipality covers a total area of $795.7 \mathrm{~km}^{2}, 49 \%$ of which within the city limits, and has a population of $1,080,113$, of which $20.3 \%$ are under 15 years of age, while $98.3 \%$ of the total population lives in the urban area.

Health administration in the municipality is divided into five Health Districts, which in turn are subdivided into the above-mentioned ACCS. Each of the 47 areas has its territory demarcated according to the population's ease of access and is sized to provide healthcare and public health services to approximately 20,000 inhabitants.

\section{Dengue data}

The study analyzed all laboratory-confirmed dengue cases from January 1st to December 31st, 2007 , since this was the year with the highest 
incidence of the disease in the city. The data were obtained from the Information System on Diseases of Notification (SINAN), provided by the Coordinating Division for Environmental and Health Surveillance of the Campinas Municipal Health Secretariat (COVISA/SMS). The variables collected in the SINAN database and included in the spatial analysis were: residential address (street name and number) and age.

After revision and correction of the notified data 15, cases' addresses were georeferenced with ArcMap 9.2 (Environmental Systems Research Institute Inc., Redlands, USA) according to the following parameters: Hayford International Ellipsoid Universal Mercator Projection, Datum Horizontal Córrego Alegre, Minas Gerais. After obtaining the latitude and longitude coordinates, cases were geocoded in the Campinas digital map base containing the ACCS grid furnished by the Municipal Health Secretariat, using the Maptools package from R 2.15.0 (The R Foundation for Statistical Computing, Vienna, Austria; http://www.r-proj ect.org).

The database resulting from this geocoding process was subdivided according to the age group of cases: 0 to 14 years and above 14 years. In a final stage, cases were aggregated by ACCS in each of these two databases.

\section{Socio-environmental deprivation strata}

To differentiate between the ACCS according to socio-environmental conditions, the 47 ACCS were classified by constructing a socio-environmental deprivation index. The classification summarized variables from the population census of 2000, some of which used in previous studies $13,15,16$. The following indicators were used: proportion of heads of households with income up to three times the minimum wage; proportion of heads of households with up to three years of schooling; proportion of households with inadequate sewage disposal; and proportion of households with inadequate garbage disposal.

Principal components analysis (PCA) was used for this purpose, based on the PRINCOMP procedure from SAS v. 9.2 (SAS Inst., Cary, USA). Next, considering the first principal component obtained with PCA and the FASTCLUS procedure from SAS, cluster analysis was performed by the k-means non-hierarchical method with the objective of grouping the ACCS into clusters with maximum internal homogeneity and maximum heterogeneity between clusters 17 .

Finally, the socio-environmental deprivation variable was incorporated into two databases with the dengue case counts, listed by ACCS. To allow estimating dengue incidence rates, in each of these two databases the population count for each ACCS was incorporated, estimated by the Coordinating Division for Information and Information Technology of the Campinas Municipal Health Secretariat, based on census data.

\section{Spatial analysis}

For each $\operatorname{ACCS}_{i}(i=1, \ldots, 47)$, the standardized incidence ratio (SIR) was calculated according to the indirect standardized method. The overall incidence rate in Campinas was used as the reference.

Bayesian hierarchical modeling was used to model the spatial distribution of relative risk of dengue in the ACCS and to explore the association with the socio-environmental deprivation index. In mapping diseases with aggregate data, a classical approach to relative risk analysis is the application of the model proposed by Besag, York, and Molliè (BYM model) 18. The model assumes that the $y_{i}$ counts are conditionally independent observations with Poisson distribution, with the following formula:

$$
y_{i} \mid \eta_{i} \sim P\left(\exp \left(\eta_{i}\right)\right) \quad i=1, \ldots, 47
$$

In which $y_{i}$ are observed dengue cases and $\eta_{i}$ is the structured additive predictor 19 and denotes the relative risk logarithm for the $i^{\text {th }}$ ACCS. The predictor $\eta_{i}$ is expanded to accommodate the ICSA covariable, taking the following form:

$$
\begin{aligned}
& \eta_{i}=\alpha+\beta_{1} I C S A(\text { moderate })_{i}+ \\
& \beta_{2} I C S A(\text { high })_{i}+f_{i(s)}+f_{i(u)}
\end{aligned}
$$

In which $\alpha$ is the intercept for the log of the relative risk for all the ACCS and $\beta_{1}$ and $\beta_{2}$ are the fixed effects parameters for the ICSA variable. The terms $f_{i}^{(u)}$ and $f_{i}^{(s)}$ represent independent random effects that model the spatially unstructured and structured heterogeneity, respectively.

Since we are using the Bayesian approach, $a$ prioris were specified for the parameters $\alpha, \beta_{1}$, $\beta_{2}, f_{i}^{(u)}$, and $f_{i}^{(s)}$. For $\alpha, \beta_{1}$, and $\beta_{2}$ we assumed non-informative Gaussian prior distribution with mean equal to zero and precision (inverse of variance) equal to a 0.0000520 . The lowest possible precision parameter was adopted to reflect our lack of prior knowledge on the strength of association between dengue risk and the socioenvironmental deprivation index.

For the random components, the unstructured effects vector elements $f(u)$ are independent, and a prior distribution was assigned, specified as $f(u) \sim N\left(0, \tau_{u}=1 / \sigma_{u}{ }_{u}^{2}\right)$, in which $\sigma_{u}^{2}$ is the unstructured variability. The spatially structured effect vector $f(s)$ is adjusted by a 
Gaussian Markov Random Field (GMRF) 19. The GMRF has its structure determined by an intrinsic Gaussian conditional autoregressive model $(C A R)$ :

$f_{i}^{(s)} \mid f_{-i}^{(s)}, \tau^{(s)} \sim N\left(\frac{1}{n_{i}} \sum_{j \in \partial_{i}} f_{j}^{(s)}, \frac{1}{n_{i} \tau^{(s)}}\right)$

In which $\partial_{i}$ represents the set of ACCS neighboring on ACCS $i$ and $\eta_{i}$ corresponds to the number of ACCS neighboring on ACCS $i$. Specification of the CAR distribution depends on a single parameter $\tau^{(s)}=1 / \sigma_{s}^{2}$, in which $\tau^{(s)}$ and $\sigma_{s}^{2}$ represent the precision and spatially structured conditional variability, respectively. The CAR distribution is inappropriate, and since inappropriate $a$ prioris can result in inappropriate $a$ posteriori, the model in equation (2) may present problems in identifying the parameters. To solve this problem, a zero sum restriction is placed on effect $f_{i}^{(s)}$, namely $\sum_{i=1}^{47} f_{i}^{(s)}=0$.

To finalize the specification of the model's parameters, the two unknown precision hyperparameters $\tau^{(s)}$ and $\tau^{(u)}$ are specified according to non-informative hyperprioris with gamma distribution $\mathrm{G}(0.5$; 0.0005), according to standard recommendations from the literature 21,22. This specification allows obtaining greater variability in the random effects estimates, allowing the data's likelihood to dominate the information contained in the $a$ priori, which would thus have little effect on inference of the a posteriori distribution of the relative risks.

All the parameters were estimated using Bayesian inference, based on Integrated Nested Laplace Approximations (INLA) 23. This method was developed to allow approximate Bayesian inference within the class of latent Gaussian models, permitting the approximation of target a posteriori marginals. Its development emerged as an alternative to Monte Carlo Markov Chain (McMC) methods, in which inference is performed via simulations. The INLA method, in turn, performs direct approximations to the target $a$ posteriori distributions. It thereby becomes possible to perform inference at a considerably lower computational cost, besides not having to deal with problems of convergence.

In the modeling process for relative risk of dengue, the analyses were stratified by age groups: 0 to 14 years and over 14 years of age and the following models were constructed by population stratum:

$$
\begin{aligned}
& \mathrm{M} 1 \mathrm{Y} \sim f_{i}^{(u)} \\
& \mathrm{M} 2: \mathrm{Y} \sim f_{i}^{(\mathbf{s})} \\
& \mathrm{M} 3: \mathrm{Y} \sim f_{i}^{(u)}+f_{i}^{(\mathbf{s})}
\end{aligned}
$$

$$
\mathrm{M} 4: \mathrm{Y} \sim f_{i}^{(u)}+f_{i}^{(\mathbf{s})}+\mathrm{ICSA}
$$

Age brackets were thus stratified due to the increasing incidence and severity of dengue in individuals under 14 years of age 2 .

The models were compared and selected using the deviance information criterion (DIC). Lower DIC values indicate better fit for the model 21. In addition, for each ACCS the study calculated and mapped the $a$ posteriori probability that the relative risk (RR) of dengue would be greater than one $[\operatorname{Pr}(R R>1 \mid Y)]$, thus obtaining a measure of statistical evidence of excess risk in each area. A posteriori probability estimates greater than 0.8 represent evidence of excess risk. Simulation studies ${ }^{24}$ demonstrated that the classification of areas at "excess risk", with a posteriori probability above the 0.8 threshold, displays good predictive capacity to detect regions with true RR around 1.5 to 2.0 when the expected counts in each region are around 20 or to detect RR close to 3 when the expected counts are small. The Bayesian modeling was performed with the $\mathrm{R}$ 2.15.0 software, using the R-INLA package (http:// www.r-inla-org).

\section{Results}

In 2007, 11,519 dengue cases were reported by the Epidemiological Surveillance System in Campinas, resulting in an incidence rate of 1,089.4 cases per 100.000 inhabitants. For all these notified cases, georeferencing identified 8,982 residential addresses $(78 \%)$ on the city's street grid. Nonidentification of the remaining cases was due to discrepancies between the addresses and the map base.

The age profile of cases showed that $15.8 \%$ were 14 years or younger, with 612.2 cases per 100,000. In the over-14 age bracket, incidence was $1,027.3$ cases per 100,000.

The socio-environmental deprivation index resulted in stratification of the ACCS in three major groups. Of the 47 ACCS, 17 (36\%) were classified in the stratum with the low socio-environmental deprivation, 21 (45\%) in the moderate stratum, and 9 (19\%) in the stratum with the high deprivation.

Comparison of incidence rates with the socioenvironmental deprivation index and by age group shows that dengue incidence increases from the lowest to the highest level of socio-environmental deprivation in both age groups separately and for cases as a whole (Table 1).

Spatial distribution of socio-environmental deprivation according to ACCS (Figure 1) shows the heterogeneity of the population's living condi- 
Population, number of cases, and dengue incidence according to socio-environmental deprivation index and age group. Campinas, São Paulo State, Brazil, 2007.

\begin{tabular}{|c|c|c|c|}
\hline $\begin{array}{l}\text { Age group/Socio-environmental } \\
\text { deprivation index }\end{array}$ & Population & Total cases & $\begin{array}{r}\text { Incidence rate } \\
\text { (per 100,000) }\end{array}$ \\
\hline$\leq 14$ years & 63,460 & 254 & 400.3 \\
\hline Low deprivation & 104,246 & 666 & 638.9 \\
\hline Moderate & 64,409 & 501 & 777.8 \\
\hline \multicolumn{4}{|l|}{ High deprivation } \\
\hline$>14$ years & 291,643 & 1,943 & 666.2 \\
\hline Low deprivation & 306,500 & 3,681 & $1,201.0$ \\
\hline Moderate & 137,899 & 1,937 & $1,404.7$ \\
\hline \multicolumn{4}{|l|}{ High deprivation } \\
\hline \multicolumn{4}{|l|}{ Total } \\
\hline Low deprivation & 355,103 & 2,197 & 618.7 \\
\hline Moderate & 410,746 & 4,347 & $1,058.3$ \\
\hline High deprivation & 202,308 & 2,438 & $1,205.1$ \\
\hline
\end{tabular}

tions in Campinas. Socio-environmental deprivation increases from the center to the periphery of the city.

Table 2 shows the models evaluated by the BYM model and respective deviance information criterion (DIC) values. For dengue cases in the age group $\leq 14$ years, the four models displayed very close DIC values. Considering that lower DIC values indicate better fit in the model, inclusion of the spatially structured effect improved the models' fit, while inclusion of the ICSA covariable in the M4 model did not improve the fit. The M3 model, adjusted for the unstructured $f(u)$ and spatially structured random effects $f(\mathrm{~s})$ displayed a lower DIC value, i.e., it was the model with the best fit. Thus, hereinafter when referring to analysis of dengue $R R$ in the age group $\leq 14$ years, we will only be using the M3 model.

The adjusted models for cases in the age group > 14 years also showed very close DIC values. The M8 model, adjusted for the effect of socioenvironmental deprivation and random effects $f$ (u) and $f(\mathrm{~s})$, was the model showing the best fit. Table 3 shows the a posteriori estimates of dengue RR according to the fixed effect of the socio-environmental deprivation index. RR estimates in the age group $>14$ years increase when moving from the lowest to the highest socio-environmental deprivation category. The RR and respective confidence intervals in the ACCS with moderate and high deprivation were, respectively, 1.77 (95\%CI: $1.33 ; 2.79)$ and 2.24 (95\%CI: $1.27 ; 3.95)$ times higher than in the ACCS with low socio-environmenta deprivation.
Figure 2 shows the smoothed estimates for dengue RR and a posteriori probabilities of the risk being greater than 1 for the age groups $\leq 14$ years and $>14$ years, obtained with the BYM model. Relative risk varied from 0.2 to 5.8 and from 0.3 to 5.7 in the age groups $\leq 14$ years and $>14$ years, respectively. For both age groups, higher relative risks were identified in ACCS located in the southern and northern regions of the city.

The dengue risk spatial distribution pattern by age group (Figure 2) proved to be similar in relation to the identification of ACCS with excess risk $[\operatorname{Pr}(\mathrm{RR}>1 \mid \mathrm{Y})>0.8]$. These ACCS displayed excess risk for the population as a whole, regardless of age group. Excess risk was observed in 17 ACCS for the age group $\leq 14$ years and in 23 for the age group $>14$ years. These areas should thus receive special attention from dengue control activities in Campinas.

\section{Discussion}

The study's results revealed differences in the spatial distribution of dengue risk in small areas of the municipality of Campinas and showed that socio-environmental indicators are associated with dengue incidence in the city. Spatial distribution of dengue incidence rates according to the socio-environmental deprivation index points to greater risk of the disease in areas with heavier socio-environmental deprivation.

Since 1999, the ACCS in the southern region of the city showed high dengue incidence 


\section{Figure 1}

Spatial distribution of the socio-environmental deprivation index according to levels of deprivation by health center coverage area. Campinas, São Paulo State, Brazil, 2007.
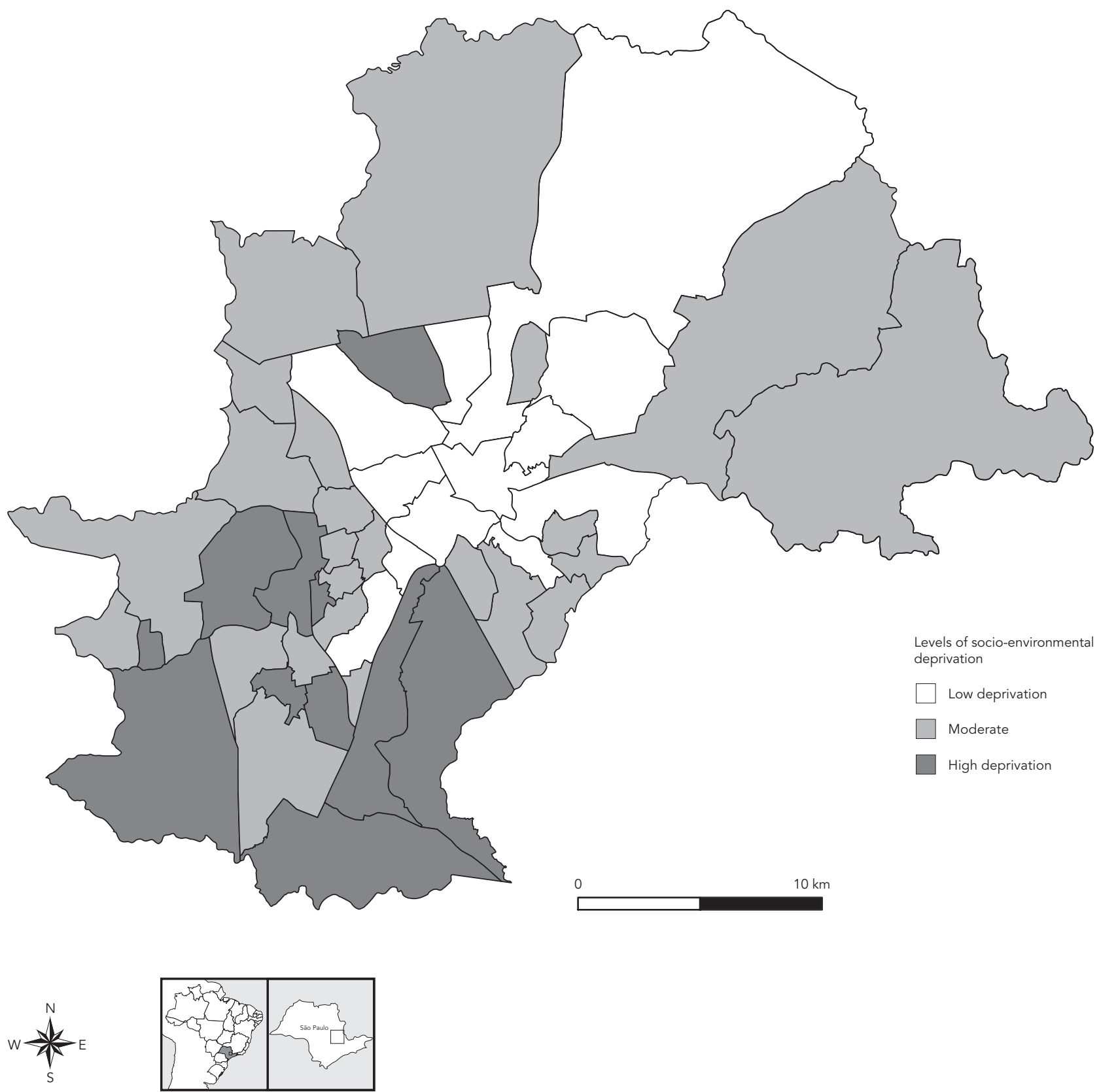

rates 25. Although the epidemic in 2007 showed the highest incidence rates in Campinas as a whole, the precarious socio-environmental conditions in the southern region and the increased viral circulation in previous years (with a decrease in susceptibles) may be associated with the greater risk of the disease in children under 14 years. 


\begin{tabular}{ll}
\hline Age group (years)/Adjusted models & Deviance information criterion (DIC) \\
\hline 14 & 416.35 \\
M1: $f(\mathrm{u})$ & 414.76 \\
M2: $f(\mathrm{~s})$ & 413.71 \\
M3: $f(\mathrm{u})+f(\mathrm{~s})$ & 413.84 \\
M4: $f(\mathrm{u})+f(\mathrm{~s})+$ socio-environmental deprivation index & \\
$>14$ & 416.72 \\
M5: $f(\mathrm{u})$ & 415.41 \\
M6: $f(\mathrm{~s})$ & 413.93 \\
M7: $f(\mathrm{u})+f(\mathrm{~s})$ & 412.89 \\
M8: $f(\mathrm{u})+f(\mathrm{~s})+$ socio-environmental deprivation index & \\
\hline
\end{tabular}

$f(\mathrm{~s})$ : spatially structured random effect; and $f(\mathrm{u})$ : unstructured random effect.

A study of viral circulation in previous years could explain the fact that some areas were not as heavily affected by the epidemic in 2007 .

The precarious living conditions in peripheral neighborhoods of Campinas could be modulating factors for greater dengue incidence. The ACCS with high relative risk and with excess risk in the northern part of the city are also areas with precarious urban infrastructure and located next to the municipality of Sumaré, also in São Paulo State, in areas of urban sprawl with high dengue incidence rates in recent decades. The southern region of the city underwent recent urbanization, with squatting settlements, heavy population concentration, and precarious socioeconomic indicators and deficient urban infrastructure in terms of basic sanitation, garbage collection, intermittent water supply, etc. 25 .

In poor areas lacking urban infrastructure the impact of vector control may be limited, with no direct or indirect results in eliminating foci of Aedes aegypti, a vector that is highly adapted to urban areas 1,26,27.

A spatial case-control study in the southern region of Campinas showed that factors related to water storage, frequency of garbage collection, and type of sewage disposal were associated with dengue incidence 25 . Although the vector's proliferation is not directly related to sewage disposal coverage, this factor indirectly reflects precarious housing conditions and poor access to urban equipment and services 27 . These results corroborate Brazilian 15,16,28,29 and international studies that relate dengue incidence to socioenvironmental conditions $20,21,22,23,24,25,26,27,28,29$, $30,31,32,33$. Higher viral circulation in these areas results in higher incidence rates in children living in neighborhoods with precarious services.

Meanwhile, Mondini \& Chiaravalloti-Neto 15 failed to find a spatial correlation between dengue incidence and socioeconomic factors in municipalities in São Paulo. Similar results have been reported in the city of Rio de Janeiro 34 , Nova Iguaçu (Rio de Janeiro State) 35, and Queensland, Australia 36 .

The contradictory results of different studies demonstrate the complex relationship between socio-environmental factors and risk of infection. Dengue transmission also undergoes interference from such factors as herd immunity to the various serotypes circulating in the current epidemic and in previous years 36 . Some authors found evidence of the association between dengue risk and socio-environmental conditions after the introduction of a new serotype, where after the virus spreads, the incidence rates generally occur in all socioeconomic strata 37 . Importantly, the current study analyzed areas in Campinas where the disease had already circulated in previous years, certainly interfering in the incidence rates in 2007.

The discrepant results between living conditions and incidence can also be explained by the process of production of the disease itself, whereby conditions in the domestic microenvironment may be more relevant that the environment's contextual characteristics at the macro-social level 38. Meanwhile, studies show different levels of spatial aggregation in the epidemiological data as well as in the use of indicators for health and living conditions with various capacities for discrimination and approximation with target 


\section{Figure 2}

Spatial distribution of relative risk (RR) and a posteriori probability of RR being greater than 1 , for age groups $\leq 14$ years $[f(\mathrm{u})+f(\mathrm{~s})]$ and $>14$ years [socioenvironmental deprivation index $+f(\mathrm{u})+f(\mathrm{~s})]$. Campinas, São Paulo State, Brazil, 2007.

2a) $\leq 14$ years $(R R)$

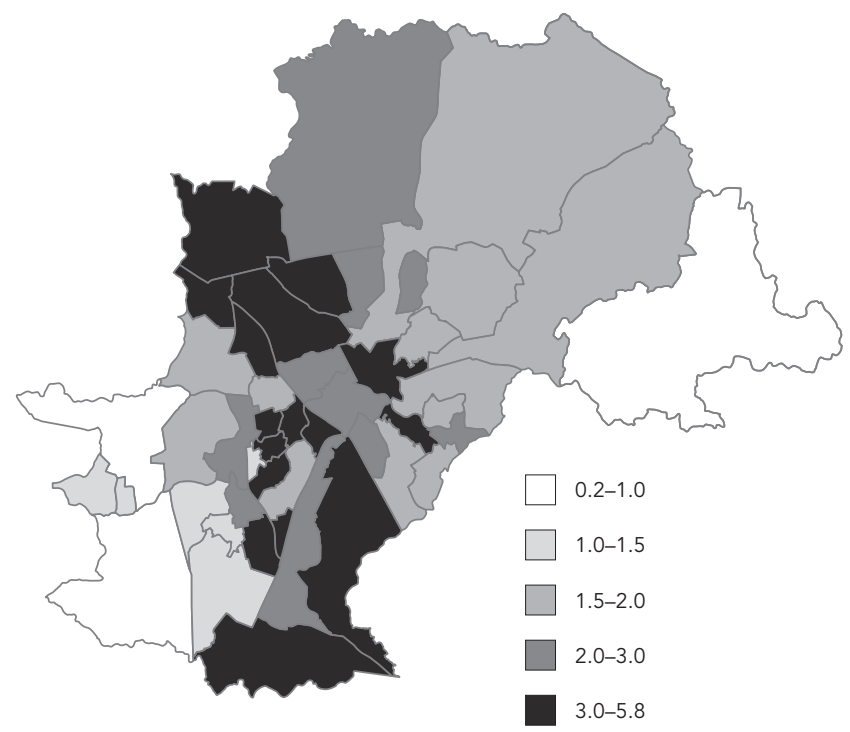

2c) $>14$ years (RR)

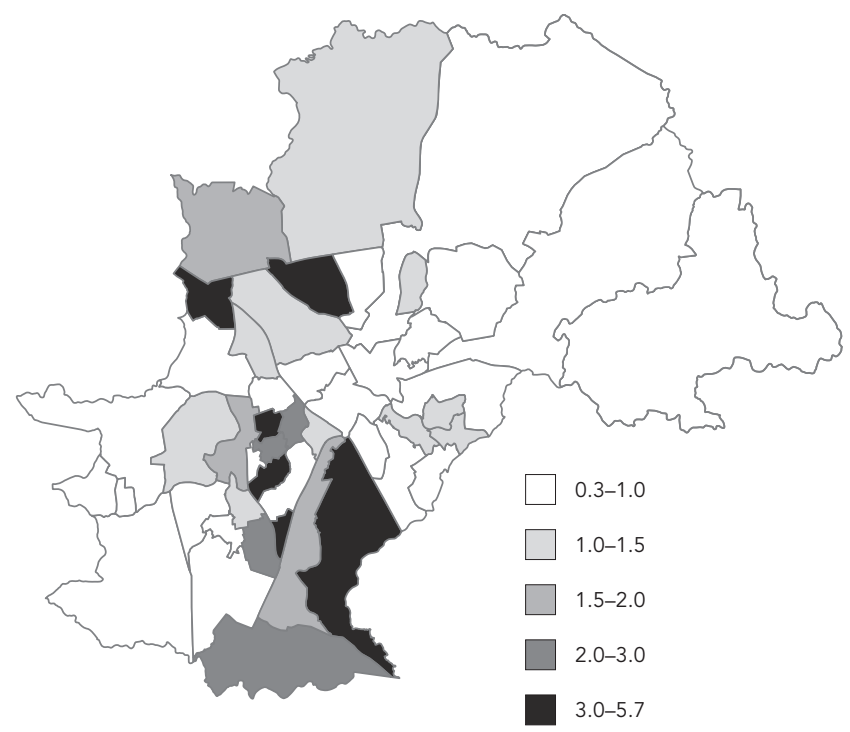

$2 b) \leq 14$ years (a posteriori of probability of RR $>1$ )

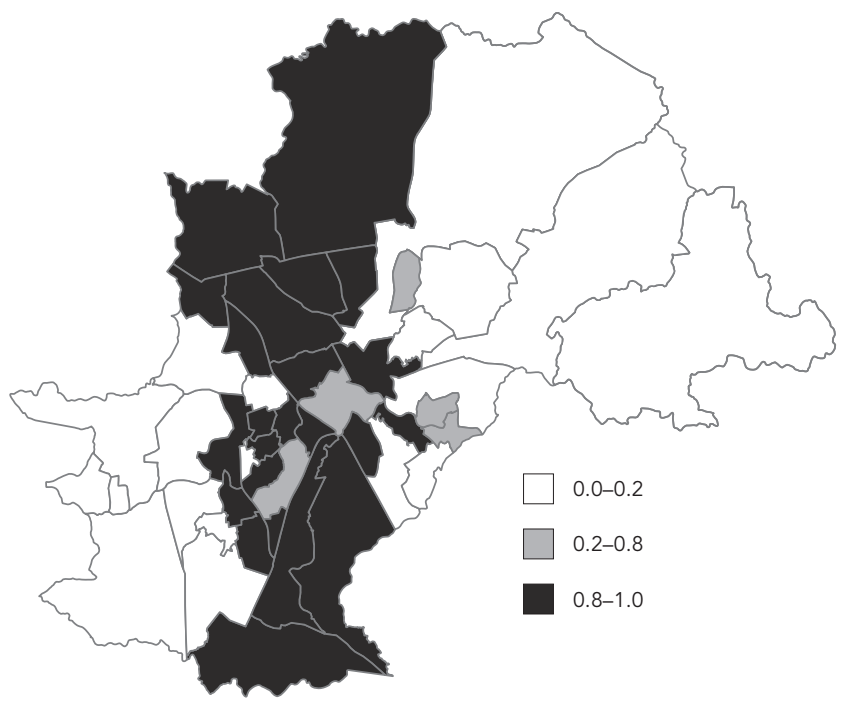

2d) $>14$ years (a posteriori of probability of RR $>1$ )

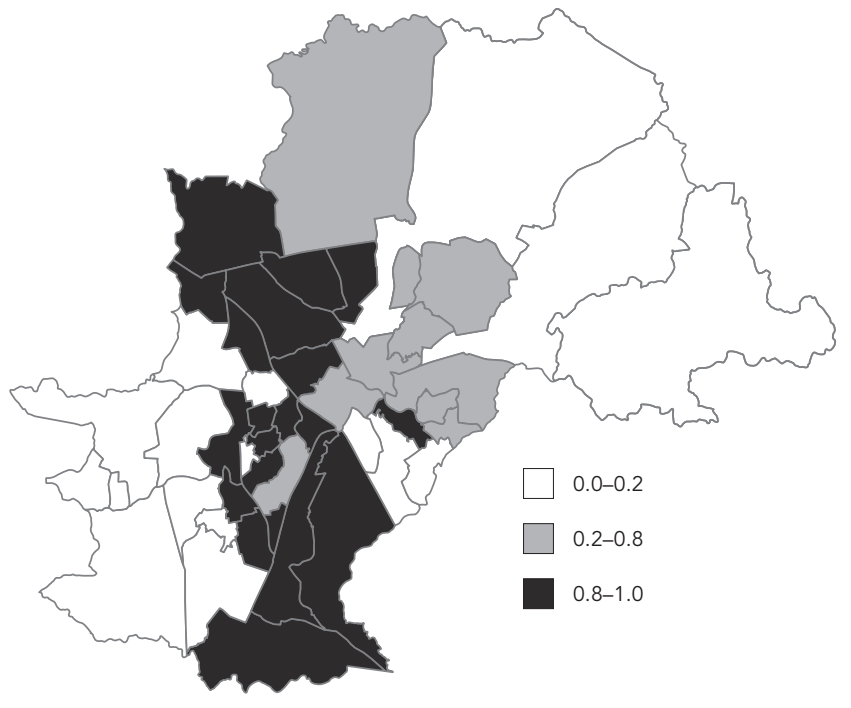

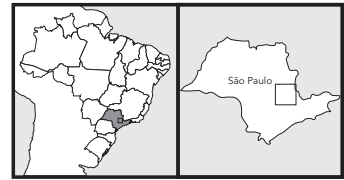


A posteriori estimates obtained by the BYM model, standard deviation (SD), relative risk (RR), and respective $95 \%$ confidence intervals $(95 \% \mathrm{Cl})$ for the > 14-year age group. Campinas, São Paulo State, Brazil, 2007.

\begin{tabular}{lccc}
\hline Variable & Estimate $(95 \% \mathrm{Cl})$ & SD & RR (95\%Cl) \\
\hline $\begin{array}{l}\text { Intercept } \\
\text { Socio-environmental deprivation index }\end{array}$ & $-0.39(-0.67 ;-0.17)$ & 0.17 & \\
$\quad$ Low deprivation & 1.00 & & $1.77(1.13 ; 2.77)$ \\
$\quad$ Moderate & $0.57(0.23 ; 1.02)$ & 0.22 & $2.24(1.27 ; 3.95)$ \\
$\quad$ High deprivation & $0.81(0.47 ; 1.38)$ & 0.29 & \\
\hline
\end{tabular}

contextual exposures for dengue transmission 38 . The choice of the ACCS as the territorial unit of analysis facilitated identification of demarcated areas for action by specific vector control and epidemiological surveillance teams in the city.

Although other factors also help explain dengue incidence, the data suggest that socio-environmental conditions are an important part of this phenomenon.

The lack of an effective vaccine for dengue prevention shifts the efforts to vector control 1 . The higher incidence rates observed in the southern region of Campinas, repeating what occurred in the epidemics in 1999 and 2002, point to the challenges of interventions to counteract risk factors for vector proliferation and dengue transmission.

On the one hand, vector control measures such as household inspections, elimination and treatment of mosquito breeding sites, and health education and social mobilization can lead to interruption of the dengue transmission cycle. Meanwhile, investments in basic sanitation, water supply, garbage collection, and access to education also have an impact on controlling the disease 39

This study featured the use of geoprocessing and spatial analysis techniques, integrating the socio-environmental data available in the 2000 population census (Instituto Brasileiro de Geografia and Estatística. http://www.ibge.com. br) and the database of dengue cases recorded in the National System for Diseases of Notification (SINAN). These techniques allow raising hypotheses on possible risk factors for dengue, identifying demarcated areas at increased risk in order to allow timely intervention 40 . The spatial unit of analysis adopted in this study, the Municipal Health Center Coverage Area (ACCS), identifies areas with dengue risk that coincide with areas used in the organization of disease prevention and control measures and action by municipal health services.
The study also highlighted the application of sensitive hierarchical Bayesian spatial models for evaluating dengue incidence and establishing associations with socio-environmental indicators within the municipal territory of Campinas. The selected statistical modeling allowed controlling the spatial correlation between neighboring ACCS and statistically comparing dengue risk in more deprived geographic areas as compared to others with less socio-environmental deprivation.

Finally, since this was an ecological study, generalization of the results and causal inference are difficult, since the study is subject to ecological bias or problems with the modifiable area unit 41 , i.e., different forms of spatial aggregation of cases can influence the effects of the relationship between risk factors and disease. We thus suggest studying the effects of the socio-environmental conditions considering different levels of geographic aggregation as well as the time dimension. We also highlight the lack of information on the circulation of the different serotypes in the study areas, which hinders interpretation of the spatial distribution of the disease and its correlation with intensity of transmission.

\section{Conclusions}

Mapping the strata of socio-environmental deprivation and dengue incidence rates proved to be a useful tool for analyzing data from the dengue surveillance systems. Relative risk estimates proved to be associated with the areas of heaviest socio-environmental deprivation. The socio-environmental deprivation index was significant, but the interpretation of its effects needs to be combined with other types of information on vector ecology, circulating serotypes, and herd immunity. 


\section{Resumen}

El objetivo de este estudio fue analizar la distribución espacial del riesgo de dengue y su relación con condiciones socioambientales. Se trata de un estudio ecológico del cómputo de los casos de dengue autóctono, en el Municipio de Campinas, estado de São Paulo, Brasil, año 2007, englobados en 47 áreas de cobertura de los centros de salud del municipio. Los modelos espaciales de mapeamiento de enfermedades se construyeron utilizándose modelos jerárquicos bayesianos, a través del método de Integración Aproximada Anidada de Laplace (INLA). Los análisis fueron estratificados según los grupos de edad de hasta 14 años y por encima de 14 años. Los resultados indican que la distribución espacial del riesgo de dengue no está asociada a condiciones socioambientales para el grupo de edad de hasta 14 años. En el grupo de edad por encima de 14 años, el riesgo relativo de dengue aumenta significativamente, conforme aumenta el nivel de escasez socioambiental. El mapeamiento de los estratos de escasez socioambiental y de los casos de dengue se mostró una herramienta útil en el análisis de los datos de los sistemas de vigilancia del dengue.

Dengue; Condiciones Sociales; Analisis de Área Pequeña; Vigilancia Epidemiológica

\section{References}

1. Gubler DJ. Dengue and dengue hemorrhagic fever: its history and resurgence as a global public health problem. In: Gubler DJ, Kuno G, editors. Dengue and dengue hemorrhagic fever. London: CAB International Press; 1997. p. 1-22.

2. Teixeira MG, Costa MC, Barreto F, Barreto ML. Dengue: twenty-five years since reemergence in Brazil. Cad Saúde Pública 2009; 25 Suppl 1:S7-18.

3. Coordenadoria de Vigilância em Saúde, Secretaria Municipal de Saúde, Prefeitura Municipal de Campinas. Informe dengue: situação atual e risco do próximo verão. http://2009.campinas.sp.gov.br/ saude/vigilancia/informes/InformeDengueOutu bro2010.pdf (accessed on 12/Apr/2012).

4. Hino P, Santos CC, Santos MO, Cunha TN, Santos CB. Evolução temporal da dengue no município de Ribeirão Preto, São Paulo, 1994 a 2003. Ciênc Saúde Coletiva 2010; 15:233-8.

5. Câmara FP, Gomes AF, Santos GTD, Câmara DCP. Clima e epidemias de dengue no Estado do Rio de Janeiro. Rev Soc Bras Med Trop 2009; 42:137-40.

\section{Contributors}

J. V. Costa participated in the study design, data analysis, discussion of the results, and writing and revision of the paper. M. R. Donalisio collaborated in the study design, discussion of the results, and writing and revision of the paper. L. V. A. Silveira contributed to the study design and participated in the data analysis and revision of the paper.

\section{Acknowledgments}

To Heloísa Girardi Malavasi for geocoding of dengue cases. To CAPES for the doctoral scholarship for the principal author.
6. Lambrechts L, Paaijmans KP, Fansiri T, Carrington LB, Kramer LD, Thomas MB, et al. Impact of daily temperature fluctuations on dengue virus transmission by Aedes aegypti. Proc Natl Acad Sci U S A 2011; 108:7460-5.

7. Alirol E, Getaz L, Stoll B, Chappuis F, Loutan L. Urbanization and infectious diseases in a globalised world. Lancet Infect Dis 2011; 11:131-41.

8. Gubler DJ. Emerging vector-borne Flavivirus diseases: are vaccines the solution? Expert Rev Vaccines 2011; 10:563-5.

9. Eisen L, Lozano-Fuentes S. Use of mapping and spatial and space-time modeling approaches in operational control of Aedes aegypti and dengue. PLoS Negl Trop Dis 2009; 3:e411.

10. Lawson A, Biggeri A, Böhning D, Lesaffre E, Viel JF, Bertollini R. Disease mapping and risk assessment for public health. Chichester: John Wiley; 1999.

11. Elliott P, Wakefield J, Best N, Briggs D. Spatial epidemiology: methods and applications. London: Oxford University Press; 2001. 
12. Siqueira JB, Martelli CMT, Maciel IJ, Oliveira RM, Ribeiro MG, et al. Household survey of dengue infection in central Brazil: spatial point pattern analysis and risk factors assessment. Am J Trop Med Hyg 2004, 71:646-51.

13. Mondini A, Chiaravalloti-Neto F. Spatial correlation of incidence of dengue with socioeconomic, demographic and environmental variables in a Brazilian city. Sci Total Environ 2008; 393:241-8.

14. Malavasi HG. Análise espacial da epidemia de dengue em Campinas/SP no ano de 2007 [Dissertação de Mestrado]. Campinas: Faculdade de Ciências Médicas, Universidade Estadual de Campinas; 2011.

15. Mondini A, Chiaravalloti Neto F. Socioeconomic variables and dengue transmission. Rev Saúde Pública 2007; 41:923-30.

16. Resendes APC, Silveira NAPR, Sabroza PC, SouzaSantos R. Determinação de áreas prioritárias para ações de controle da dengue. Rev Saúde Pública 2010; 44:274-82.

17. Hair Jr. JF, Black WC, Babin, BJ, Anderson R.E, Tatham RL. Multivariate Data Analysis. $6^{\text {th }}$ Ed. Upper Saddle River: Pearson Prentice Hall; 2006.

18. Besag J, York J, Molli A: Bayesian image restoration, with two applications in spatial statistics. Ann Inst Stat Math 1991; 43:1-20.

19. Fahrmeir L, Lang S. Bayesian inference for generalized additive mixed models based on Markov random field priors. J R Stat Soc Ser C Appl Stat 2001; 50:201-20.

20. Kelsall J, Wakefield J. Discussion of "Bayesian models for spatially correlated disease and exposure data”. In: Bernardo J, Berger J, Dawid A, Smith A editors. Bayesian Statistics 6. Oxford: Oxford University Press; 1999. p. 131-56.

21. Knorr-Held L, Rue H. On block updating in Markov random field models for disease mapping. Scand Stat 2002; 29:597-614.

22. Spiegelhalter DJ, Best NG, Carlin BP, van der Linde A. Bayesian measures of model complexity and fit. J R Stat Soc Series B Stat Methodol 2002; 64: 583-639.

23. Rue H, Martino S, Chopin N. Approximate Bayesian inference for latent Gaussian models by using integrated nested Laplace approximations. J R Sta Soc Series B Stat Methodol 2009; 71:319-92.

24. Richardson S, Thomson A, Best N, Elliott P. Interpreting posterior relative risk estimates in diseasemapping studies. Environ Health Perspect 2004; 112:1016-25

25. Cordeiro R, Donalisio MR, Andrade VR, Mafra AC Nucci LB, Brown JC, Stephan C. Spatial distribution of the risk of dengue fever in southeast Brazil, 2006-2007. BMC Public Health 2011; 11:355.

26. Kuno G. Factors influencing the transmission of dengue viruses. In: Gubler DJ, Kuno G, editors. Dengue and dengue hemorrhagic fever. London: CAB International Press; 1997. p. 61-88.

27. Guzmán MG, Kourí G. Dengue: an update. Lance Infect Dis 2002; 2:33-42.
28. Almeida ASD, Medronho RDA, Valencia LIO. Spa tial analysis of dengue and the socioeconomic context of the city of Rio de Janeiro (Southeastern Brazil). Rev Saúde Pública 2009; 43:666-73.

29. Pessanha JEM, Caiaffa WT, Kroon EG, Proietti FA. Dengue em três distritos sanitários de Belo Horizonte, Brasil: inquérito soroepidemiológico de base populacional, 2006 a 2007. Rev Panam Salud Pública 2010; 27:252-8.

30. Nagao Y, Svasti P, Tawatsin A, Thavara U. Geographical structure of dengue transmission and its determinants in Thailand. Epidemiol Infect 2008; 136:843-51

31. Thammapalo S, Chongsuvivatwong V, Geater A, Dueravee M. Environmental factors and incidence of dengue fever and dengue haemorrhagic fever in an urban area, Southern Thailand. Epidemiol Infect 2008; 136:135-43.

32. Spiegel JM, Bonet M, Ibarra A-M, Pagliccia N Ouellette V, Yassi A. Social and environmental determinants of Aedes aegypti infestation in Central Havana: results of a case-control study nested in an integrated dengue surveillance programme in Cuba. Trop Med Int Health 2007; 12:503-10.

33. Reiter P, Lathrop S, Bunning M, Biggerstaff B, Singer D, Tiwari T, et al. Texas lifestyle limits transmission of dengue virus. Emerg Infect Dis 2003; 9:86-9.

34. Teixeira TRA, Cruz OG. Spatial modeling of dengue and socio-environmental indicators in the city of Rio de Janeiro, Brazil. Cad Saúde Pública 2011; 27:591-602.

35. Machado JP, Oliveira RMD, Souza-Santos R. Análise espacial da ocorrência de dengue e condições de vida na cidade de Nova Iguaçu, Estado do Rio de Janeiro, Brasil. Cad Saúde Pública 2009; 25: 1025-34.

36. Hu W, Clements A, Williams G, Tong S, Mengersen K. Spatial patterns and socioecological drivers of dengue Fever transmission in Queensland, Australia. Environ Health Perspect 2012; 120:260-6.

37. Mondini A, Bronzoni RVM, Nunes SHP, Chiaravalloti Neto F, Massad E, Alonso WJ, et al. Spatio-temporal tracking and phylodynamics of an urban dengue 3 outbreak in São Paulo, Brazil. PLoS Negl Trop Dis 2009; 3:e448.

38. Flauzino RF, Souza-Santos R, Barcellos C, Gracie R, Magalhães MAFM, Oliveira RMD. Heterogeneida de espacial da dengue em estudos locais, Niterói, RJ. Rev Saúde Pública 2009; 43:1035-43.

39. World Health Organization. Dengue guidelines, for diagnosis, treatment, prevention and control. New edition. Geneva: World Health Organization; 2009

40. Teixeira TRA, Medronho RA. Indicadores sóciodemográficos e a epidemia de dengue em 2002 no Estado do Rio de Janeiro, Brasil. Cad Saúde Pública 2008; 24:2160-70.

41. Openshaw S. Ecological fallacies and the analysis of areal census data. Environ Plann A 1984; 16: 17-31.

Submitted on 30/Jul/2012

Final version resubmitted on 06/Nov/2012

Approved on 14/Feb/2013 